\title{
Methodological Approach for Assessment of the Radioactivity Level in Dry Solid Waste
}

\author{
Tomohiro Nagamatsu ${ }^{1), 2)}$, Akihiro Sakoda ${ }^{2)}$, Katsumi Hanamoto ${ }^{2)}$, Ikuo Kinno ${ }^{1)}$, \\ Tadashi Hanafusa $^{1)}$, Kiyonori Yamaoka ${ }^{2)}$ and Toshiro Ono ${ }^{1)}$ \\ 1) Department of Radiation Research, Advanced Science Research Center, Okayama University \\ 2) Department of Radiation Technological Science, Graduate School of Health Sciences, Okayama University
}

Received Oct. 7, 2008; accepted Dec.12, 2008

Under the Law Concerning Prevention from Radiation Hazards due to Radioisotopes etc., the radioactive dry solid waste is composed into drums at an on-site warehouse until collection and disposal at the storage facility of the Japan Radioisotope Association (JRIA). The radioactivity levels of such dry solid waste that have been previously assumed and recorded by the experimental researchers have sometimes been in error. A methodological approach was investigated for re-evaluation of radioactivity in dry solid waste, prior to shipment to the JRIA for future disposal at a landfill site. The radioactivity of ${ }^{51} \mathrm{Cr}$ - and ${ }^{125} \mathrm{I}$-contaminated wastes generated from biomedical research was measured. In the ${ }^{51} \mathrm{Cr}$-contaminated wastes, the measured radioactivity always showed higher values, ranging between 1.4 to 9.9 times that of the recorded radioactivity. In the ${ }^{125} I$-contaminated wastes, 4 of 5 combustible type 2 samples showed 4.1 to 28.6 times higher measured radioactivities than those initially recorded. The ratio of measured versus used radioactivity was also evaluated. This study may contribute a fair assessment of the radioactivity levels in biomedical waste prior to shipment to the disposal sites, and thus afford protection of human health and the environment.

Key words: radioactive waste, dry solid waste, $\gamma$-emitter, ${ }^{51} \mathrm{Cr}$, ${ }^{125} \mathrm{I}$

\section{Introduction}

Any activity that uses radioisotopes generates radioactive wastes in gas, liquid and solid form. Most waste from hospitals and scientific research is low-level radioactive waste (LLRW), which is comprised of organic fluids, water-treatment residues and dry solid waste such as paper, rags, clothing, gloves, plastic tools etc. Under the Law Concerning Prevention from Radiation Hazards due to Radioisotopes etc. (Prevention Law), dry solid waste must be compacted into drums and stored in an on-site storage facility until collection and disposal at the storage facility of the Japan Radioisotope Association (JRIA). The waste is then shipped to the storage facility of the Tokai Research Establishment, Japan Atomic Energy Research (JAER).

Some medical wastes are incinerated at the Takizawa Laboratory, JRIA. However, the final disposal of non-medical wastes is not allowed, and they must therefore be stored at the JAER facility. To date, approximately 2 million 50liter drums of

Department of Radiation Research, Advanced Science Research Center, Okayama University

2-5-1 Shikata-cho, Okayama 700-8558, Japan
LLRW are awaiting final disposal ${ }^{1}$. Space at the JAER facility and at on-site warehouses is limited and decreasing. In 2006, a revised Prevention Law was finally described for the construction and operation of a landfill site for disposal of LLRW in the near future. In this study, a methodological approach for the reevaluation of radioactivity in dry solid waste was investigated, with an aim to assess levels of radioactivity prior to shipment to JRIA for future disposal at a landfill site.

\section{Material and Methods}

\subsection{Measuring method}

The most frequently used $\gamma$-emitter in this facility are two medium-lived radionuclides, ${ }^{51} \mathrm{Cr}$ and ${ }^{125} \mathrm{I}$, and those were used for the experiment. Dry solid waste was separated into 3 types, combustible type 1 , combustible type 2 and incombustible waste, and was packaged into $1,000 \mathrm{~cm}^{3}$ plastic containers. The radioactivity of ${ }^{51} \mathrm{Cr}$ and ${ }^{125} \mathrm{I}$ was obtained using a $\gamma$-ray spec- 
trometry (Aloka JSM-1403, Mitaka, Tokyo, Japan) with $7.6 \mathrm{~cm}$ $\times 7.6 \mathrm{~cm} \mathrm{NaI}(\mathrm{Tl})$ detector (Aloka ADP-130, $1.8 \mathrm{~mm}$ thickness of aluminum window). Energy window of $270-370 \mathrm{keV}$ for ${ }^{51} \mathrm{Cr}$ and $15-45 \mathrm{keV}$ for ${ }^{125} \mathrm{I}$ was employed, respectively (Fig. 1).

\subsection{Mock samples}

For preliminary experiment, 3 types of mock samples were prepared and packaged in plastic containers. These samples were paper, rubber gloves and aluminum sheet as combustible type 1, combustible type 2 and incombustible waste, respectively. 0.185 to $7.4 \mathrm{kBq}$ of $\mathrm{Na}^{51} \mathrm{CrO}_{4}$ (Amersham Biosciences, Piscataway, NJ) and $\mathrm{Na}^{125} \mathrm{I}$ (Amersham Biosciences) were added to the same samples, and radioactivity was then measured.

\subsection{Experimental samples}

Actual dry solid combustible type 1 and combustible type 2 wastes generated from following biomedical research using ${ }^{51} \mathrm{Cr}$ and ${ }^{125} \mathrm{I}$ were collected from 5 consecutive experiments conducted by the same researchers. No incombustible waste was generated from these experiments.

1) Cell-mediated cytotoxicity assay ${ }^{2)}$

Human tumor cells were labeled with $\mathrm{Na}_{2}{ }^{51} \mathrm{CrO}_{4}$ (Amersham Biosciences) for $1 \mathrm{hr}$ at $37^{\circ} \mathrm{C}$ under $5 \% \mathrm{CO}_{2}$ in air. After washing, ${ }^{51} \mathrm{Cr}$-labelled tumor cells were incubated with tumor specific cytotoxic $\mathrm{T}$ lymphocyte lines. After incubation for $4 \mathrm{hr}$ at $37^{\circ} \mathrm{C}$ under $5 \% \mathrm{CO}_{2}$ in air, the supernatans were removed and their radioactivity was measured. Combustible type 1 waste consisted of paper, and combustible type 2 waste

Combustible type 1

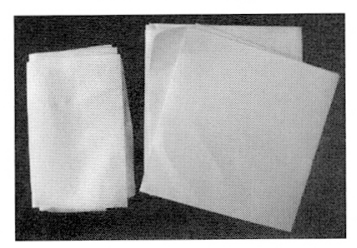

Combustible type 2
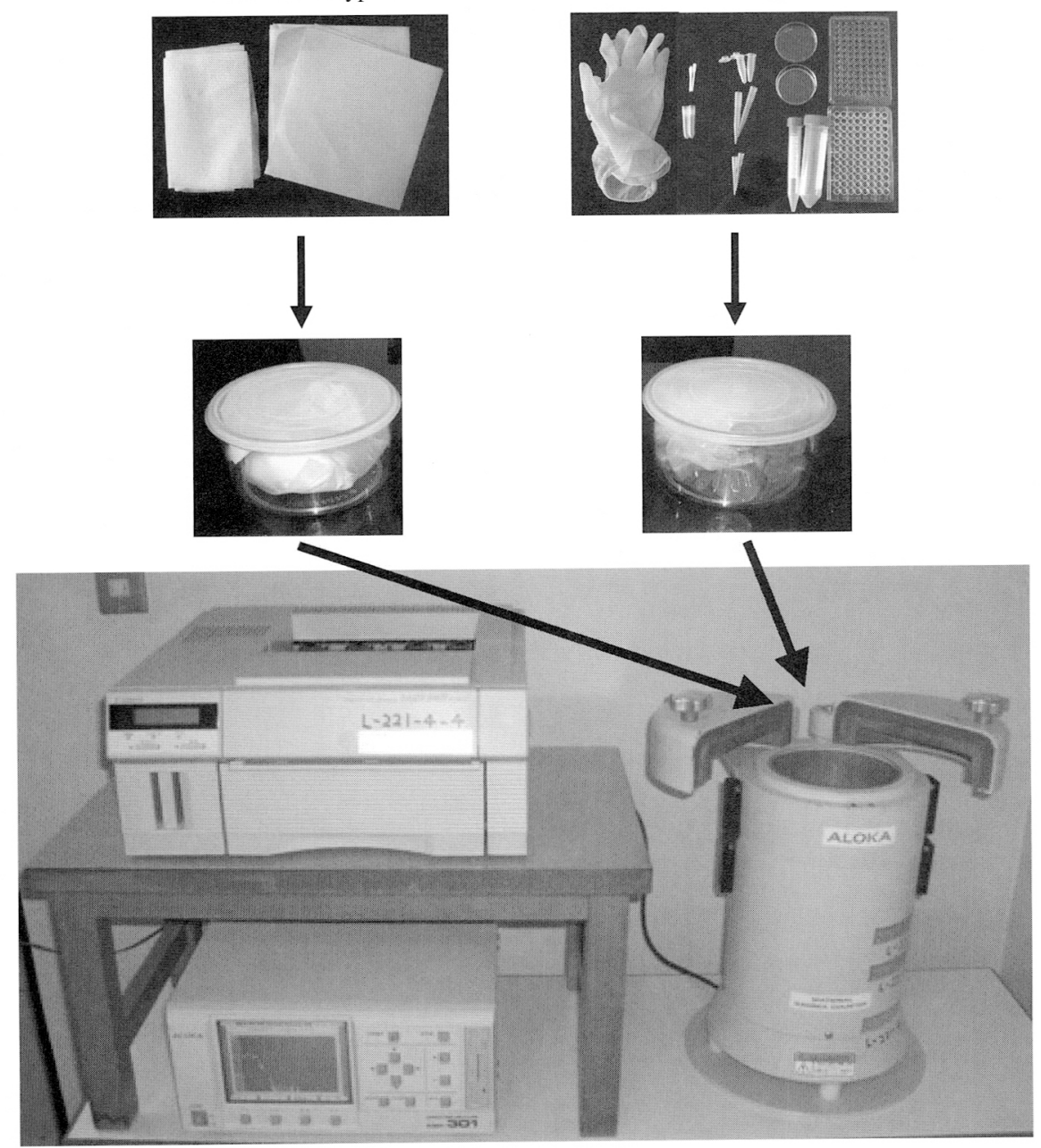

Measuring system

Fig. 1 Measuring system. Each waste sample was packaged into $1,000 \mathrm{~cm}^{3}$ plastic containers. They were placed in the well of the $\gamma$-ray spectrometry and radioactivity was measured. 
consisted of rubber gloves, cotton swabs and plastic tools including tubes $(1.5,15$, and $50 \mathrm{ml})$, dishes (35 mm diameter), pipette tips and 96 well microplates.

2) Binding assay of low-density lipoprotein (LDL) to macrophages $^{3)}$

Isolated human LDL was radioiodinated using $\mathrm{Na}^{125} \mathrm{I}$ (Amersham Biosciences) and Iodo-gen pre-coated tubes (Pierce, Rockford, IL) according to the manufacturer's instruction. ${ }^{125} \mathrm{I}$ labelled LDL ( $\left.{ }^{125} \mathrm{I}-\mathrm{LDL}\right)$ was purified by gel chromatography. ${ }^{125} \mathrm{I}-\mathrm{LDL}$ was added to the macrophage cell line. After incubation for $2 \mathrm{hr}$ at $4^{\circ} \mathrm{C}$, the cells were washed to remove unbound ${ }^{125}$ I-LDL. The cells were lysed using $0.1 \mathrm{~N} \mathrm{NaOH}$ and the cellassociated radioactivity was measured. Combustible type 1 waste consisted of paper, and combustible type 2 waste consisted of rubber gloves, and plastic tools including tubes (1.5, 2, and $50 \mathrm{ml}$ ), pipettes, pipette tips and 96 well microplates.

The radioactivity measured from this waste was then compared with equivalent records estimated by the experimental researchers.

\section{Results}

\subsection{Measurement of mock waste samples}

${ }^{51} \mathrm{Cr}$ and ${ }^{125}$ I were added to the mock samples and their count rates were measured separately, and plotted against activity. As shown in Fig. 2, linear plots were obtained in the activity range up to $7.4 \mathrm{kBq}$. The average relative standard deviations for each data point in the plots were less than $10 \%$ with 5 replicates for each data point. The counting efficiencies were calculated based on the plots. As shown in Table 1, the same counting efficiencies were obtained for ${ }^{51} \mathrm{Cr}$ in 3 different types of waste sample.
However, for ${ }^{125} \mathrm{I}$ in the combustible type 2 waste sample, a much lower counting efficiency was obtained compared with those in the combustible type 1 and incombustible waste samples.

\subsection{Measurement of actual waste samples}

To precisely determine the radioactivity levels of actual dry wastes, ${ }^{51} \mathrm{Cr}$ - and ${ }^{125} \mathrm{I}$-contaminated wastes generated from biomedical research were used. As shown in Table 2, for the ${ }^{51} \mathrm{Cr}$ contaminated combustible type 1 and combustible type 2 wastes, all measured activities showed higher values, ranging from 1.4 to 9.9 times the recorded activities estimated by the researches. On the other hand, there were considerable discrepancies between the measured and recorded activities in the ${ }^{125} \mathrm{I}$ contaminated wastes (Table 3). The combustible type 2 waste samples had activities that were 4.1 to 28.6 times higher than those of recorded. The radioactivity of the ${ }^{51} \mathrm{Cr}$ - contaminated wastes decreased with elapsed time, and was identical to the theoretical decay curves derived from ${ }^{51} \mathrm{Cr}$ (Fig. 3).

\section{Discussion}

The Department of Radiation Research, Shikata Laboratory, Advanced Science Research Center (Shikata Laboratory) is a core facility for radioisotope research in Okayama University with 200 permitted radiation handling workers. Shikata Laboratory generates LLRW in large amounts in the form of dry solid waste, liquid waste, and animal carcasses. This waste contains short and medium-lived radionuclides $\left({ }^{32} \mathrm{P},{ }^{35} \mathrm{~S},{ }^{51} \mathrm{Cr}\right.$, ${ }^{99 \mathrm{~m}} \mathrm{Tc}$, and $\left.{ }^{125} \mathrm{I}\right)$, and long-lived radionuclides $\left({ }^{3} \mathrm{H}\right.$ and $\left.{ }^{14} \mathrm{C}\right)$. The majority of the waste is in the form of dry solids, which are composed of disposable gloves, paper towels, plastic tools, glass (a)

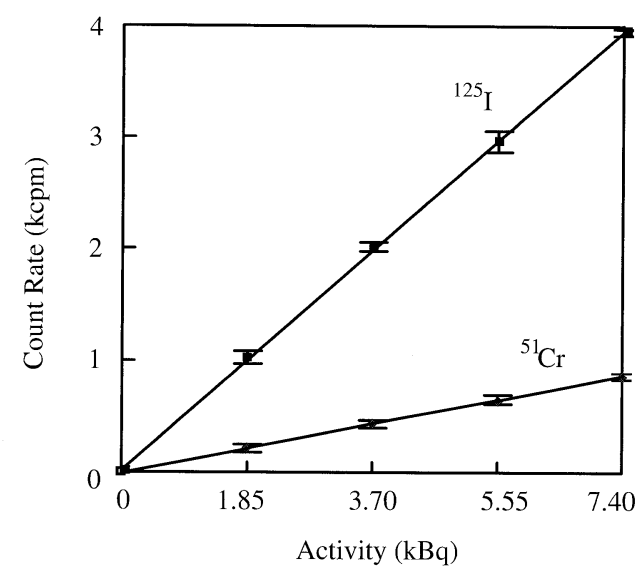

(b)

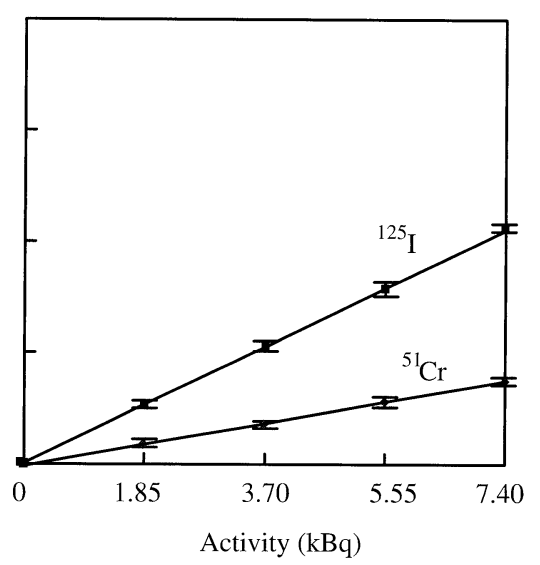

(c)

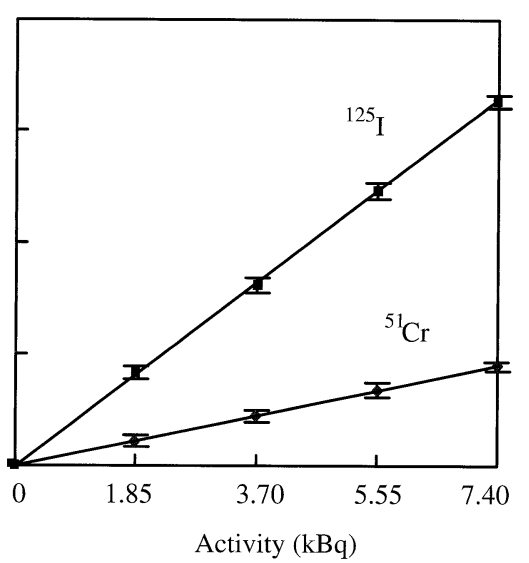

Fig. 2 Correlation between count rate and the radioactivity added $\left(0.185\right.$ to $7.4 \mathrm{kBq}$ of ${ }^{51} \mathrm{Cr}$ and $\left.{ }^{125} \mathrm{I}\right)$ to the mock samples; (a) combustible type 1, (b) combustible type 2, and (c) incombustible mock samples. 
Table 1 Counting Efficiency

\begin{tabular}{ccc}
\hline Mock Samples & Radionuclide & Counting Efficiency \\
\hline Combustible type 1 & ${ }^{51} \mathrm{Cr}$ & $1.9 \times 10^{-3}$ \\
(paper) & ${ }^{125 \mathrm{I}}$ & $8.8 \times 10^{-3}$ \\
Combustible type 2 & ${ }^{51} \mathrm{Cr}$ & $1.7 \times 10^{-3}$ \\
(rubber gloves) & ${ }^{125}$ & $4.7 \times 10^{-3}$ \\
Incombustible & ${ }^{51} \mathrm{Cr}$ & $2.0 \times 10^{-3}$ \\
(aluminum sheet) & ${ }^{125}$ & $7.5 \times 10^{-3}$ \\
\hline
\end{tabular}

Table $2{ }^{51} \mathrm{Cr}$-contaminated Waste

\begin{tabular}{|c|c|c|c|c|}
\hline \multirow{2}{*}{ Samples } & \multicolumn{3}{|c|}{ Record } & \multirow{2}{*}{ Measurement $(\mathrm{kBq})$} \\
\hline & Used $(\mathrm{kBq})$ & & $\mathrm{ed}(\mathrm{kBq})$ & \\
\hline \multirow{2}{*}{1} & \multirow{2}{*}{4715.0} & $A^{1)}$ & 47.2 & $353.2 \pm 56.4$ \\
\hline & & $\mathrm{B}^{2)}$ & 424.4 & $603.7 \pm 73.7$ \\
\hline \multirow{2}{*}{2} & \multirow{2}{*}{$4,775.8$} & $A^{1)}$ & 47.8 & $135.3 \pm 34.9$ \\
\hline & & $\mathrm{B}^{2)}$ & 429.8 & $860.8 \pm 78.3$ \\
\hline \multirow{2}{*}{3} & \multirow{2}{*}{$4,510.5$} & $A^{1)}$ & 45.1 & $176.0 \pm 39.8$ \\
\hline & & $\mathrm{B}^{2)}$ & 405.9 & $1,125.2 \pm 100.6$ \\
\hline \multirow{2}{*}{4} & \multirow{2}{*}{$4,918.6$} & $A^{1)}$ & 49.2 & $488.8 \pm 66.3$ \\
\hline & & $\mathrm{B}^{2)}$ & 442.7 & $1,863.6 \pm 129.5$ \\
\hline \multirow{2}{*}{5} & \multirow{2}{*}{$6,211.4$} & $A^{1)}$ & 62.1 & $173.1 \pm 39.5$ \\
\hline & & $B^{2)}$ & 559.0 & $1,819.0 \pm 127.9$ \\
\hline
\end{tabular}

1) Combustible type 1 waste

2) Combustible type 2 waste

Table $3{ }^{125}$ I-contaminated Waste

\begin{tabular}{|c|c|c|c|c|}
\hline \multirow{2}{*}{ Samples } & \multicolumn{3}{|c|}{ Record } & \multirow{2}{*}{ Measurement $(\mathrm{kBq})$} \\
\hline & Used $(\mathrm{kBq})$ & & osed $(\mathrm{kBq})$ & \\
\hline \multirow{2}{*}{1} & \multirow{2}{*}{$65,970.4$} & $A^{1)}$ & 66.0 & $20.9 \pm 13.7$ \\
\hline & & $B^{2)}$ & $26,388.2$ & $21,664.2 \pm 441.6$ \\
\hline \multirow{2}{*}{2} & \multirow{2}{*}{$65,970.4$} & $A^{1)}$ & 33.0 & $1.3 \pm 3.4$ \\
\hline & & $B^{2)}$ & 329.9 & $9,426.7 \pm 291.3$ \\
\hline \multirow{2}{*}{3} & \multirow{2}{*}{$30,650.0$} & $A^{1)}$ & 3.1 & $1.1 \pm 3.1$ \\
\hline & & $B^{2)}$ & 153.3 & $1,059.5 \pm 97.6$ \\
\hline \multirow{2}{*}{4} & \multirow{2}{*}{$21,153.4$} & $A^{1)}$ & 4.2 & $0.1 \pm 0.9$ \\
\hline & & $B^{2)}$ & 435.9 & $1,789.2 \pm 126.9$ \\
\hline \multirow{2}{*}{5} & \multirow{2}{*}{$15,855.6$} & $A^{1)}$ & 0.5 & $21.5 \pm 13.9$ \\
\hline & & $\mathrm{B}^{2)}$ & 237.8 & $4,193.5 \pm 194.3$ \\
\hline
\end{tabular}

1) Combustible type 1 waste

2) Combustible type 2 waste 
(a)

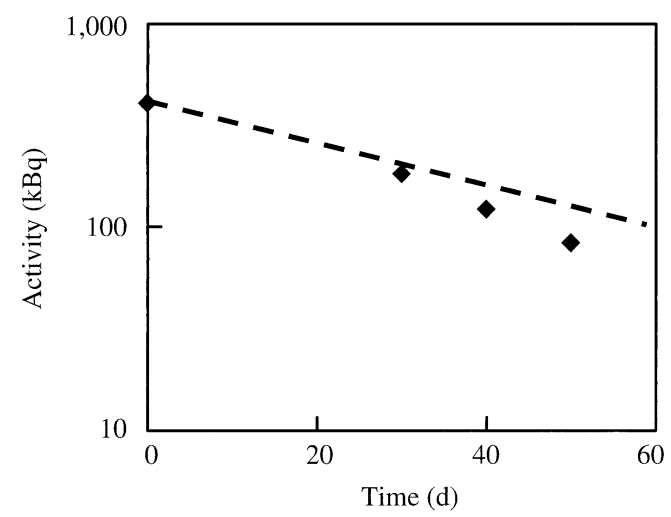

(b)

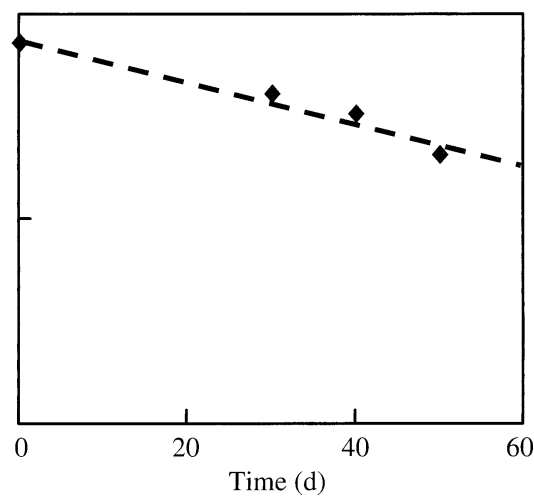

Fig. 3 Measurement of ${ }^{51} \mathrm{Cr}$ radioactivity in the collected solid waste samples. The dashed lines indicate the theoretical decay curves for ${ }^{51} \mathrm{Cr}$; (a) combustible type 1 waste, and (b) combustible type 2 waste.

vials, and other contaminated objects. The waste containing long-lived radionuclides is disposed of in a radioavctive waste container separate from waste containing short and mediumlived materials.

In this study, the activity of dry solid waste containing medium-lived $\gamma$-emitters such as ${ }^{51} \mathrm{Cr}$ and ${ }^{125} \mathrm{I}$ was analyzed immediately after disposal, in order to make an assessment of the precise levels of radioactivity prior to shipment to JRIA and future disposal at a landfill site. All measured activities in the ${ }^{51} \mathrm{Cr}$-contaminated wastes showed higher values than the recorded radioactivity estimated by the experimental researchers. For the ${ }^{125}$ I-contaminated combustible type 2 wastes, 4 samples had measured activities showed 4.1 to 28.6 times higher than those recorded. In another series of experiments, a combustible type 2 sample had measured activity 117 times higher than the recorded activity (data not shown). The recorded activity turned to have been underestimated by the researcher, revealing that this assessment is a reasonable re-evaluation system. The ratio of measured versus used activity revealed a maximum of $10 \%$ for the ${ }^{51} \mathrm{Cr}$-containing combustible type 1 waste and $38 \%$ for the ${ }^{51} \mathrm{Cr}$-containing combustible type 2 waste generated from the cell-mediated cytotoxicity assay, and a maximum of $0.3 \%$ for the ${ }^{125} \mathrm{I}$-containing combustible type 1 waste and $26 \%$ for the ${ }^{125}$ I-containing combustible type 2 waste generated from the LDL binding assay, respectively. On the other hand, the combustible type 2 waste samples showed much lower counting efficiency for ${ }^{125} \mathrm{I}$ compared with those in the other types of waste. It should be further investigated whether the lower counting efficiency for ${ }^{125} \mathrm{I}$ can be obtained in the combustible type 2 waste samples.
Space in the JAER warehouse is limited and disposal is currently cost-prohibitive. A landfill site will finally be constructed and operated in the near future. However, such disposal requires attention with respect to the protection of human health and the environment. Considering this, the present study may confirm the necessity for assessment of the radioactivity levels in waste prior to shipment to the disposal site, and could thus lead to savings in LLRW disposal costs. Again, present study may suggest a valid methodological system for the re-evaluation of radioactivity level in dry solid waste.

\section{Acknowledgements}

We thank Drs. Aji, T. and Kobayashi, K. (Graduate School of Medicine, Dentistry and Pharmaceutical Science, Okayama University) for assistance with the radioactive waste collection. We also thank Prof. Yamada, M. (Graduate School of Medicine, Dentistry and Pharmaceutical Sciences, Okayama University) for support this study.

\section{References}

1. http://www.asahi.com/national/update/0205/TKY200802050185.html 2. Okumura, H., Noguchi, Y., Uenaka, A., Aji, T., Ono, T., Nakagawa, K., Aoe, M., Shimizu, N. and Nakayama, E.: Identification of an HLA-A24-restricted OY-TES-1 epitope recognized by cytotoxic Tcells. Microbiol. Immunol., 49, 1009-1016 (2005).

3. Kobayashi, K., Tada, K., Itabe, H., Ueno, T., Liu, P.-H., Tsutsumi, A., Kuwana, M., Yasuda, T., Shoenfeld, Y., de Groot, P. G. and Matsuura, E.: Distinguished effects of antiphospholipid antibodies and anti-oxidized LDL antibodies on oxidized LDL uptake by macrophages. Lupus, 16, 929-938 (2007). 